\title{
Repair of meniscal defect using an induced myoblast-loaded polyglycolic acid mesh in a canine model
}

\author{
YANGLIN GU, WENHUI ZHU, YUEDONG HAO, LIANGYU LU, YANG CHEN and YUBIN WANG \\ Department of Sports Medicine, Dongfang Hospital Affiliated to Tongji University, Shanghai 200120, P.R. China
}

Received September 27, 2011; Accepted November 29, 2011

DOI: $10.3892 /$ etm.2011.403

\begin{abstract}
Defects of the meniscus greatly alter knee function and predispose the joint to degenerative changes. The purpose of this study was to test a recently developed cellscaffold combination for the repair of a critical-size defect in the canine medial meniscus. A bilateral, complete resection of the anterior horn of the medial meniscus was performed in 18 Beagle canines. A PLGA scaffold was implanted into the defect of one knee of 6 canines and the contralateral defect was left untreated. Scaffolds loaded with autologous myoblasts and cultured in a chondrogenic medium for 14 days were implanted in a second series of 12 canines. Empty scaffolds were implanted in the contralateral knees. Menisci were harvested at 12 weeks. Untreated defects had a muted fibrous healing response. Defects treated with cell-free implants also showed predominantly fibrous tissue, whereas fibrocartilage was present in several scaffolds. The thickness of the repair tissue after treatment with cell-free scaffolds was significantly greater compared to the controls $(\mathrm{p}<0.05)$. Pre-cultured implants integrated with the host tissue, and 9 of 12 contained meniscus-like fibrocartilage when compared to 2 of the 12 controls $(\mathrm{p}<0.05)$. The thickness of the pre-cultured implant repair tissue was greater compared to the controls $(\mathrm{p}<0.05)$. This study demonstrates the repair of a critical size meniscal defect using a stem cell and scaffold-based tissue engineering approach.
\end{abstract}

\section{Introduction}

Meniscal injury is a common traumatic injury in knee and is second only to osteoarthritis. The meniscus is a complex fibrocartilaginous tissue, which is essential in the knee joint for shock absorption, load distribution, maintenance of stability and protection of articular cartilage $(1,2)$. Meniscal injury may lead to long-term degenerative joint changes, such

Correspondence to: Dr Yubin Wang, Department of Sports Medicine, Dongfang Hospital Affiliated to Tongji University, 150 Jimo Road, Shanghai 200120, P.R. China

E-mail: shtjdxgyl@yahoo.cn

Key words: meniscus, myoblasts, scaffolds, tissue engineering as osteophyte formation, articular cartilage degeneration, joint space narrowing and symptomatic osteoarthritis. Treatments of meniscal injury in the knee joint include partial or total meniscectomy, meniscus repair and allogeneic meniscus transplantation. However, these treatments are not perfect and often lead to cartilage degeneration, increase in pain and loss of function $(3,4)$.

Tissue engineering of the meniscus using stem cells and polymer scaffolds may be an alternative option to treat meniscal injury $(5,6)$. Tissue engineering may offer the use of a patient's own cells with the exact shape and size to fit the meniscal defect, which may be an ideal alternative for patients undergoing meniscal injuries (7). However, there have been several fundamental biological concerns about this technique, including the cell source, the matrix scaffold, bioreactor considerations and environmental conditions. We believe that the two major problems related to meniscal tissue engineering are cell source and meniscal scaffold.

Concerning cell source, meniscal chondrocytes, mesenchymal cells and pluripotential fibroblasts have all been identified as potential sources for the repair of meniscal tissue (8-10). Compared to the above-mentioned cell sources, myoblasts represent a more promising source for meniscal engineering, as they are relatively abundant and easily accessible with minimal donor site morbidity. At the same time, myoblasts further promote the development of tissue engineering, as they have a higher cell yield and more rapid proliferative ability during in vitro expansion (11).

In regards to the scaffold, a variety of biomaterials, either naturally derived or artificial, have been investigated for the tissue-engineered meniscus. Because of the poor biomechanical properties and the fast degradation of fibrin and alginate, polymer scaffolds with a stable, biodegradable, permeable pore network were introduced to support cell attachment and proliferation and nutrient exchange, and to provide stability. The most common of such polymers are polylactic acid (PLA), polyglycolic acid (PGA) and poly(lactic-co-glycolide acid) (PLGA). PGA has been widely used for anchoring stem cells to facilitate the generation of the meniscus in vitro or to restore damaged meniscus in vivo (12). The suitable biocompatibility of the PGA scaffold to the seed cells has been demonstrated. Moreover, in order to prepare scaffolds with specific anatomical shape and to improve mechanical stability, a certain amount of PLA solution was usually added during the processing of the PGA scaffold. Such a type of PLGA composite has been 
successfully used in healing meniscal defects using a tissue engineering approach (8).

Thus, we investigated whether myoblasts repair full thickness meniscal defects in canines with follow-up of long-term outcomes. Autologous myoblasts were first expanded and induced with cartilage-derived morphogenetic protein-2 (CDMP-2) and transforming growth factor- $\beta 1$ (TGF- $\beta 1$ ) in vitro, seeded onto a PLGA scaffold and then chondrogenically induced again. The cell-scaffold complexes, after being induced in vitro for 14 days, were implanted to treat criticalsized meniscal defects. Successful repair was achieved at 12 weeks after transplantation, indicating that autologous myoblasts, along with the PLGA scaffold, could be potentially used for meniscal repair.

\section{Materials and methods}

Isolation, culture and induction of myoblasts. Canine myoblasts were isolated and cultured as previously described (13). Primary cells were seeded on a culture dish at a density of $5 \times 10^{5}$ cells $/ \mathrm{cm}^{2}$ in Dulbecco's modified Eagle's medium (DMEM; Gibco BRL, Grand Island, NY, USA) containing $10 \%$ fetal bovine serum (FBS; Gibco BRL), $300 \mu \mathrm{g} / \mathrm{ml}$ L-glutamine, $50 \mu \mathrm{g} / \mathrm{ml}$ vitamin $\mathrm{C}, 100 \mathrm{U} / \mathrm{ml}$ penicillin $\mathrm{G}$, $100 \mu \mathrm{g} / \mathrm{ml}$ streptomycin and $0.25 \mu \mathrm{g} / \mathrm{ml}$ amphotericin B (all from Sigma, St. Louis, MO, USA). After medium change, cultured myoblasts were either subjected to chondrogenic induction, with the culture medium containing $50 \mathrm{ng} / \mathrm{ml}$ CDMP-2 and $20 \mathrm{ng} / \mathrm{ml}$ TGF- $\beta 1$ (Sigma). The myoblasts were cultured at $37^{\circ} \mathrm{C}$ in a humidified atmosphere of $95 \%$ air and $5 \% \mathrm{CO}_{2}$. The medium was replaced completely every third day, to wash out all non-adherent cells. Cells were subcultured at a density of $1.0 \times 10^{4}$ cells $/ \mathrm{cm}^{2}$ and treated with $0.25 \%$ trypsin plus $0.02 \%$ EDTA (Gibco BRL) when they reached $80 \%$ confluence.

Immunocytochemistry assay of collagen II. To determine the in vitro chondrogenic induction effect, induced myoblasts were examined for type II collagen expression with immunocytochemical staining. Briefly stated, cells were incubated at $37^{\circ} \mathrm{C}$ for $1 \mathrm{~h}$ with mouse anti-collagen II monoclonal antibody (IgG1; BD Biosciences Clontech, Franklin Lakes, NJ, USA) diluted in phosphate-buffered saline (PBS; 1:200), followed by incubation with 1:100 diluted horseradish peroxidase (HRP)conjugated anti-mouse antibody (Dako, Carpinteria, CA, USA) for $30 \mathrm{~min}$, and color development was carried out using diaminobenzidine tetrahydrochloride (DAB). Normal menisci served as positive controls.

Analysis of mRNA for extracellular matrices and collagen with reverse transcriptase-polymerase chain reaction $(R T-P C R)$. Total RNA was extracted from passage 3-induced myoblasts and normal menisci, and RT-PCR was performed to detect pro-collagen I, II and aggrecan mRNA expression. The purity and amount of isolated RNA were assessed by spectrophotometric measurement at 260 and $280 \mathrm{~nm}$. Total RNA was reverse-transcribed to cDNA at $50^{\circ} \mathrm{C}$ for $50 \mathrm{~min}$ in a volume of $20 \mu \mathrm{l}$ containing $1 \mu \mathrm{l}$ of $10 \mathrm{mM}$ dNTP mix, $1 \mu \mathrm{l}$ of $10 \mathrm{mM}$ dithiothreitol, $1 \mu \mathrm{l}$ of $50 \mu \mathrm{M}$ oligo (dT), $4 \mu \mathrm{l}$ of $5 \mathrm{X}$ first strand buffer, $1 \mu 1$ of RNase OUT and 200 U of Superscript III (RNase
$\mathrm{H}$-free RT; Gibco BRL). After terminating the reaction at $70^{\circ} \mathrm{C}$ for $15 \mathrm{~min}, 2$ units of $\mathrm{RNase} \mathrm{H}$ were added to the reaction mixture, followed by incubation at $37^{\circ} \mathrm{C}$ for $20 \mathrm{~min}$ to remove the RNA. The cDNA was diluted 1:500 and then amplified in $50 \mu \mathrm{l}$ of a PCR mixture containing $5 \mu \mathrm{l}$ of Taq buffer, $4 \mu \mathrm{l}$ of $\mathrm{MgCl}_{2}, 4 \mu \mathrm{l}$ of $10 \mathrm{mM}$ dNTP mix, 1.25 units of Taq polymerase and primer sets. PCR was performed in a minicycler, including an initial denaturation at $94^{\circ} \mathrm{C}$ for $2 \mathrm{~min}$, followed by 35 cycles of denaturation at $94^{\circ} \mathrm{C}$ for $1 \mathrm{~min}$, annealing at $54^{\circ} \mathrm{C}$ (type I collagen) and $56^{\circ} \mathrm{C}$ (type II collagen and aggrecan) for $1 \mathrm{~min}$, and extension at $72^{\circ} \mathrm{C}$ for $1 \mathrm{~min}$. The final cycle included $5 \mathrm{~min}$ of extension. The PCR products were analyzed by electrophoresis in $2 \%$ agarose gels and stained with ethidium bromide. The mRNAs analyzed were collagen I (681 bp), collagen II (447 bp), aggrecan (321 bp) and glyceraldehyde-3-phosphate dehydrogenase (GAPDH) (211 bp). Prime sequences for GAPDH, aggrecan, collagen I and collagen II were as follows: GAPDH, sense 5'CCTCTATGCCAACACAGTGC3', antisense 5'GTACTCCTGCTTGCTGATCC3'; aggrecan, sense 5'TAGAGAAGAAGAGGGGTTAGG3', antisense 5'AGCACTAGGAGCCAGGGTTAT3'; collagen I, sense 5'ATGCCCAAGACTACCAGTGG3', antisense 5'TCC TGGAAGCTCTTCTCAGT3'; collagen II, sense 5'-TTT CCCAGGTCAAGATGGTC-3', antisense 5'-CTTCAGCAC CTGTCTCACCA-3'.

Preparation of the PLGA scaffold and cell seeding. A nonwoven copolymer scaffold of L-lactide and glycolide (90/10; PLGA) in the form of fibers was generously provided by the Shanghai Ju Rui Biomaterials Company Inc., China. The scaffolds were cuboid, with a width of $2.5 \mathrm{~mm}$, a height of $2.5 \mathrm{~mm}$ and a length of $7 \mathrm{~mm}$. The pore sizes of the non-woven fibers were on average $75 \mu \mathrm{m}$, the pore volume accounts for $97 \%$ of the total volume and the filament diameter was $13 \mu \mathrm{m}$. The PLGA constructs were treated using the low-pressure plasma technique at the end of the production process. A partially ionized gas reacted with the surface of the scaffolds and formed reactive particles. Before cell seeding, the scaffolds were immersed in DMEM/F12 medium containing $10 \%(\mathrm{v} / \mathrm{v})$ FBS for $12 \mathrm{~h}$ to enhance cell adhesion onto the scaffold.

Chondrogenically induced myoblasts at passage $3\left(1.5 \times 10^{7}\right.$ in $0.3 \mathrm{ml}$ ) were harvested and dropped onto PLGA scaffolds to form cell-scaffold constructs and the constructs were cultured at $37^{\circ} \mathrm{C}$ in a humidified atmosphere of $5 \% \mathrm{CO}_{2}$ for $5 \mathrm{~h}$, which allowed complete adhesion of myoblasts to the scaffold. The cell-PLGA constructs in inductive media were subsequently cultured in vitro for 14 days. Medium was changed three times a week. As an experimental control, scaffolds without myoblasts were cultured for the same time periods.

Surgical procedure for meniscal defect. Six-month-old male Beagle canines were used in this study, and were obtained from the Agricultural Institute of Shanghai Jiaotong University, China. Animal care and experimental procedures were in accordance with the guidelines of the Administrative Panel on Laboratory Animal Care of China. The Beagle canines were anaesthetized. The model of canine meniscal defect was as follows: a defect of $2.5 \mathrm{~mm}$ in width, $2.5 \mathrm{~mm}$ in thickness near the capsule and $1.5 \mathrm{~mm}$ in thickness near the cavity, the entire length of the transverse diameter without reservation of the 


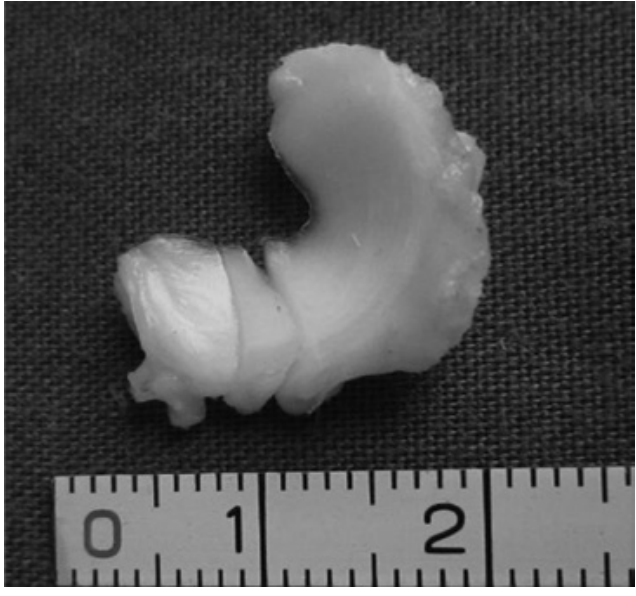

Figure 1. Description of the performed meniscal defect with removal of the complete anterior horn of the medial meniscus.

basement at the anterior horn of the meniscus $0.5 \mathrm{~cm}$ distant from the anterior edge was made, which involved the red-red, red-white and white-white areas of the meniscus (Fig. 1). The size of the resected portion was measured to ensure uniformity. In the first experiment, PLGA scaffolds were implanted in 6 canine right knees. Defects were also created in the contralateral knees and left empty to serve as controls. In the second experiment, meniscal defects in 12 animals were repaired with cell-loaded, pre-cultured PLGA scaffolds. Empty PLGA scaffolds were placed in the menisci of the contralateral knees. All animals were sacrificed at 12 weeks. Six additional canines without any surgical treatment to the knee joints were used for the histological analysis of normal meniscal architecture. The wound sites were injected with Marcaine after closure to minimize post-operative pain. All canines recovered quickly from the surgeries and none required any further pain medication. Post-operatively, the animals were allowed free movement without use of any type of immobilization.

Gross assessment of the meniscal repair. Canines with surgical implants were euthanized for tissue harvest. After exposure of the knee joint, the macroscopic morphology of the meniscus was evaluated with a stereomicroscope and photographed.

Histological and immunohistochemical analyses. Twelve weeks after implantation, the implants were retrieved and analyzed histologically and immunohistochemically. For histological analyses, specimens were fixed in $10 \%(\mathrm{v} / \mathrm{v})$ buffered formalin, dehydrated with a series of graded alcohol and embedded in paraffin. Tissue sections (4- $\mu \mathrm{m}$ thick) were stained with H\&E for morphological analysis.

Expression of collagen type I and II was detected using monoclonal antibodies (Dako). Briefly stated, after deparaffinization, sections were predigested with trypsin at $37^{\circ} \mathrm{C}$ for $30 \mathrm{~min}$ to facilitate antibody access. Endogenous peroxidase was quenched by the treatment of $0.3 \% \mathrm{H}_{2} \mathrm{O}_{2}$ in methanol at room temperature for $30 \mathrm{~min}$, and non-specific antibody binding was blocked by incubation of the sections in a $10 \%$ normal goat serum at $37^{\circ} \mathrm{C}$ for $30 \mathrm{~min}$. Mouse anti-canine collagen type I and II diluted 1:100 in 0.01 M PBS (pH 7.4) were applied as a primary antibody at $4^{\circ} \mathrm{C}$, overnight. Sections

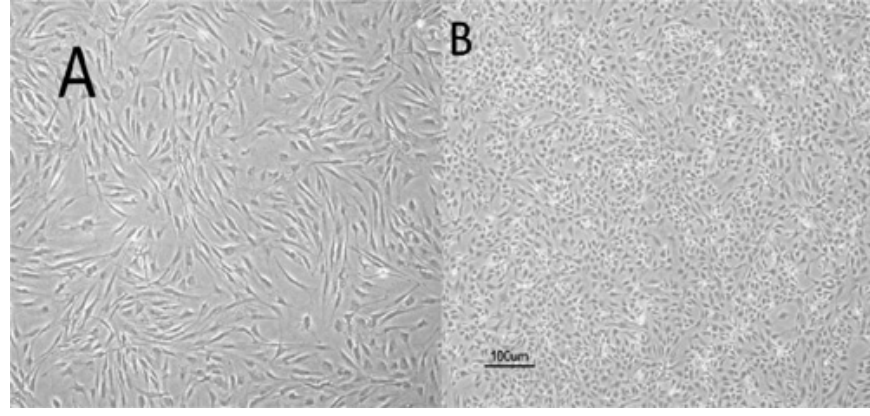

Figure 2. Morphological change between primary myoblasts and chondrogenically induced myoblasts. (A) Morphology of canine myoblasts cultured in a monolayer manner on day 3 in the primary culture. (B) Myoblasts underwent chondrogenic differentiation after 14 days. Scale bar, $100 \mu \mathrm{m}$.

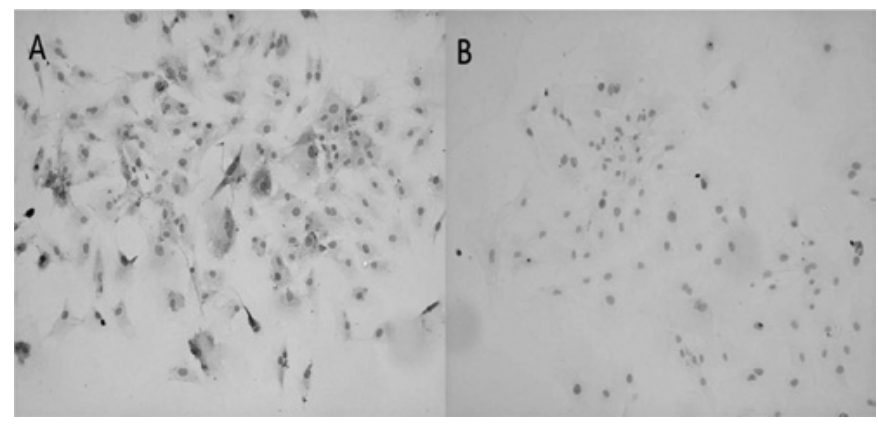

Figure 3. Immunocytochemical staining demonstrates a stronger expression of collagen II in (A) induced cells than in (B) non-induced cells. Magnification, $200 \mu \mathrm{m}$.

were then incubated with the secondary antibody, rabbit antimouse immunoglobulin (Dako) for 60 min followed by mouse PAP kit (Dako). Collagen type I and II were visualized by the reactions with $0.05 \%$ DAB containing $0.01 \% \mathrm{H}_{2} \mathrm{O}_{2}$.

In addition to the qualitative assessment of all the menisci, the thickness of the repair tissue was measured on images of H\&E-stained histological sections of menisci with a computerized image analysis system. The mean thickness of the repair zone was assessed and compared to the mean thickness of the normal menisci, harvested and processed in the same manner from 6 untreated canines.

Statistical analysis. The presence of type II collagen in the repair tissue of each meniscus of the different groups was noted and statistically compared using the Fisher's exact test. The thickness of the repair tissue was measured and the thickness in the different groups was statistically compared using two-tailed t-tests. For all evaluations, the level of statistical significance was set at a probability value of $<0.05$.

\section{Results}

Morphological change and expression of cartilage-specific genes by RT-PCR. As shown in Fig. 2A, myoblasts induced with CDMP-2 and TGF- $\beta 1$ underwent a morphological change after chondrogenic induction, approaching the shape of native chondrocytes. In addition, the induced cells showed significantly enhanced collagen I and II expression (Fig. 3) and gene levels ( $<<0.05$; Fig. 4) compared to control cells. Furthermore, 


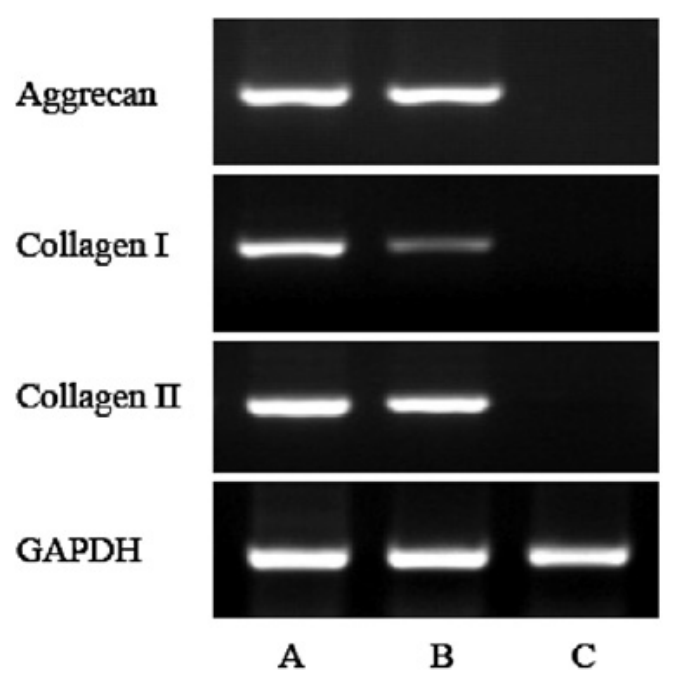

Figure 4. Analysis of the mRNA expression of aggrecan, collagen I, II and GAPDH with RT-PCR. (A) Positive control using a normal meniscus. (B) Myoblasts that underwent chondrogenic differentiation after 14 days. (C) Control cell after 2 weeks in culture.

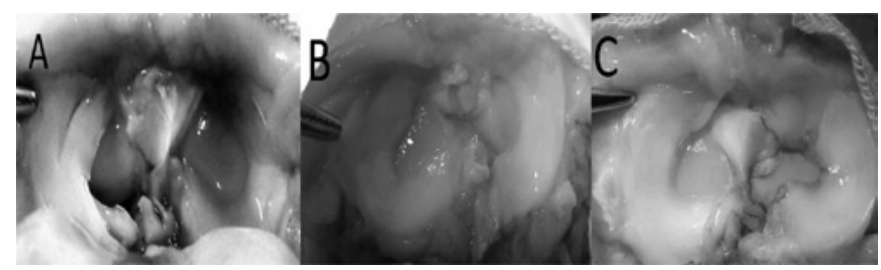

Figure 5. Gross morphology of meniscus repair in (A) untreated defect, (B) empty scaffold and (C) pre-cultured cell-scaffold composite, 12 weeks after implantation.

aggrecan gene expression was also significantly enhanced in chondrogenically induced cells ( $\mathrm{p}<0.05$; Fig. 4).

Gross morphology of the meniscal repair. In each knee that had an empty meniscal defect, only a muted healing response, consisting of a thin, fibrous-like band next to the surrounding tissue, was detected; however, most of the defect remained unfilled. The appearance of additional meniscal degeneration, such as a longitudinal tear in the anterior horn of the meniscus, was noted in 4 of the 6 empty-defect animals (Fig. 5A). Compared to the repair in these empty defects, the repair from the empty PLGA scaffolds exhibited more complete defect filling: macroscopically, good integration of the repair tissue with the anterior meniscal horns was noted in 4 of 6 animals after 12 weeks. However, there were surface irregularities in the anterior meniscal horns in all animals with implants (Fig. 5B). Meniscal repair using the pre-cultured, cell-loaded implants resulted in near-complete filling of the defects (Fig. 5C). Integration of the implant with the retained anterior horn of the meniscus was noted in all animals at 12 weeks. In comparison, in the contralateral knee with an empty composite scaffold, only 2 of the 12 animals demonstrated good integration at 12 weeks, consistent with the results of the first experiment.

Histological and immunohistochemical assessment of the meniscal repair. In the empty meniscal defects, only a thin

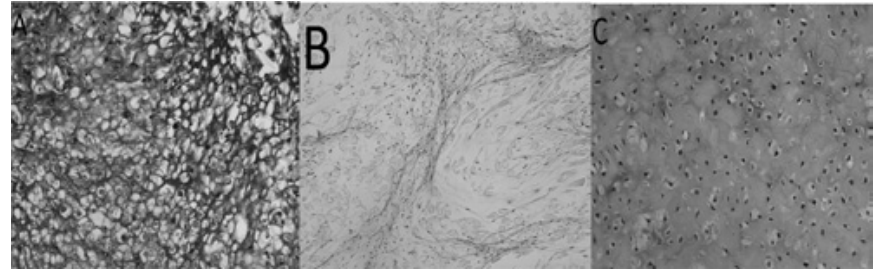

Figure 6. H\&E histology of repair tissue. (A) Untreated defect, (B) defect filled with an empty scaffold and (C) defect filled with a cell-scaffold composite, 12 weeks after implantation. Magnification, $200 \mu \mathrm{m}$.

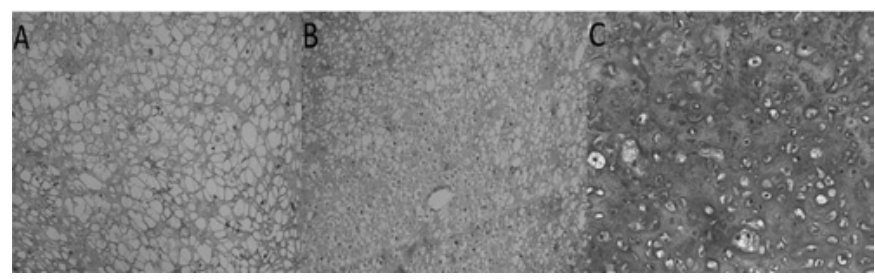

Figure 7. Type II collagen immunohistochemistry of repair tissue. (A) Untreated defect, (B) defect filled with an empty scaffold and (C) defect filled with a cell-scaffold composite, 12 weeks after implantation. Magnification, $200 \mu \mathrm{m}$.

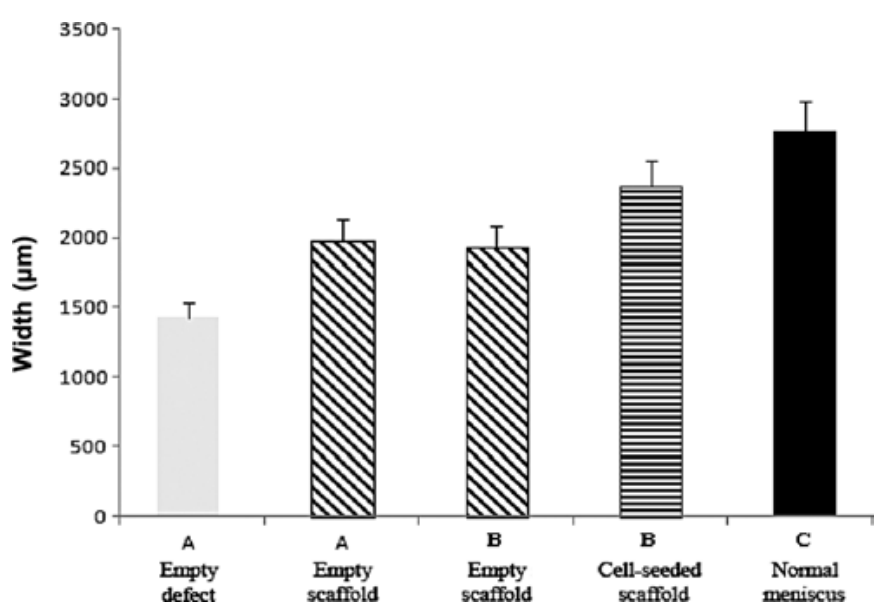

Figure 8. Thickness of meniscus repair tissue (mean \pm SD) of two different studies. (A) Animals treated with empty scaffolds in one knee joint vs. untreated controls in the opposite knee joint. (B) Animals treated with empty scaffolds in one knee joint vs. cell-seeded scaffolds in the opposite knee joint. The mean \pm SD measurements for normal meniscus width were evaluated from animals without meniscal defects and added for comparison.

band of fibrous tissue was found in the anterior meniscal horns (Fig. 6A). This stunted repair tissue consisted of non-metachromatic tissue with fibroblastic cells and high cellularity. No type II collagen expression was detected by immunohistochemistry (Fig. 7A). The repair tissue in the meniscal defects treated by the implantation of empty PLGA scaffolds also demonstrated predominantly non-metachromatic, fibrous tissue that did not contain type II collagen (Fig. 7B). In the repair tissue produced after the implantation of pre-cultured cell-scaffolds, meniscus-like fibrocartilage with hyaline cartilage-like areas was noted in 9 of the 12 animals (Fig. 7C). The contralateral knees, with an empty scaffold implant, had a fibrocartilage phenotype in only 2 of the 12 animals. The difference in the fibrocartilage regeneration between the 
cell-loaded scaffold and the empty scaffold was statistically significant $(\mathrm{p}<0.03$, Fisher's exact test).

Thickness of the repair tissue. The mean thickness of the repaired meniscal regions for all groups was determined and compared to the equivalent measurements from normal menisci. The repair tissue produced with empty PLGA scaffolds had a mean thickness of $1,975 \mu \mathrm{m}$ (Fig. 8). This repair tissue was significantly thicker $(\mathrm{p}<0.05)$ compared to that of the empty defects, which had a mean thickness of $1,428 \mu \mathrm{m}$. The mean thickness of the repair tissue in the meniscal defects that contained cell-scaffold composites was 2,367 $\mu \mathrm{m}$; significantly thicker $(\mathrm{p}<0.004)$ than the repair tissue of the comparable contralateral empty scaffold group, which had a mean thickness of $1,937 \mu \mathrm{m}$. Normal menisci had a mean thickness of 2,759 $\mu \mathrm{m}$ (Fig. 8). The cell-scaffold composite group regenerated $\sim 90 \%$ of the thickness of the normal meniscus as compared to $62 \%$ for the empty scaffold group. The results for the empty scaffold groups of the two experiments were consistent and not statistically different.

\section{Discussion}

In this study, the repair of a critical-size defect, which involved the red-red, red-white and white-white areas of the meniscus, was achieved in a canine model with the combination of a PLGA scaffold and myoblasts. An injury model was created that tested several important elements of successful tissue repair: the size and shape of the resected meniscus; the formation of tissue that has appropriate histological features; and the successful integration of the repaired tissue with the remaining structure. To achieve this, we completely resected the anterior horn of the medial meniscus in the canine knee and replaced the resected section with a biodegradable and biocompatible composite scaffold. Two different tissue-engineering strategies were used in this study: implantation of a composite scaffold alone and implantation of the scaffold that was seeded with myoblasts and pre-cultured to produce cartilaginous tissue.

In this study, we focused on myoblasts. Myoblasts, which are adult stem cells and include skeletal muscle cell precursors, have been reported to possess multipotential mesenchymal stem cell activity and are capable of forming chondrocytes, osteocytes and adipocytes as well as myocytes $(14,15)$. These reports suggest that a certain degree of plasticity remains before terminal myoblastic differentiation. Therefore, myoblasts may potentially prove very useful for the development of new therapeutic approaches aimed at the regeneration of damaged or diseased tissues. Myoblasts have been considered a candidate cell source for tissue engineering (16-18). Compared to other stem cell sources, myoblasts represent a more promising source for cartilage engineering, as they are relatively abundant and easily accessible with minimal donor site morbidity $(19,20)$. At the same time, myoblasts further promote the development of tissue engineering, as they have higher cell yield and more rapid proliferation ability during in vitro expansion $(21,22)$. In this study, we also observed a chondrogenic response, with a dose of $50 \mathrm{ng} / \mathrm{ml} \mathrm{CDMP-2}$ and $20 \mathrm{ng} / \mathrm{ml}$ TGF- $\beta 1$ given continuously with each medium change. Chondrogenic differentiation, analyzed on the immunohistochemical and gene expression profiles, was observed for the induced condition. This result suggests that key events responsible for the commitment of myoblasts to the chondrogenic lineage take place during the early initial period of cell growth and proliferation.

PGA is one of the most commonly used synthetic polymers in cartilage tissue engineering. To maintain its dimensional stability and enhance its mechanical properties, fibrous PGA meshes are always coated with solutions of PLA. Evaporation of the solvent for PLA would thus result in PLGA composites with specific shapes. The feasibility of using PLGA composite as a scaffold to engineer cartilage tissue has been well documented in a variety of studies $(23,24)$. It was also shown that adhesion and proliferation of chondrocytes on PGA fibers was significantly suppressed with the increase in the amount of PLA added. Therefore, the concentration of PLA solution to be added has to be lowered, but sufficient to function as glue to maintain the structural stability of the PGA 3-D scaffold. In our study, $1.5 \%$ PLA in dichloromethane was used, as the further lowering would result in an unstable configuration of the resultant scaffold. It was observed by SEM that PLA of this concentration wraps PGA fibers together and the shape of the scaffold is maintained well when they are maintained in culture medium for as long as 5 weeks (24).

One major advantage of using a PLGA scaffold for meniscal tissue engineering is its suitable degradation rate which matches the kinetics of new meniscal formation in vivo (8). The complete degradation of a non-woven PGA scaffold is reported to be accomplished over a period of 2 months in vivo (25). In the present study, no remnant of un-degraded PLGA fibers could be observed histologically, either in the experimental or control groups at 12 weeks post-implantation. Due to its fast degradation, the PLGA scaffold was found to be able to accelerate chondrogenesis of constructs prepared from dedifferentiated chondrocytes and PLGA, as the accumulation of the deposited cartilage-specific extracellular matrix, and expression of marker genes both in vitro and in vivo were significantly enhanced compared to those of constructs prepared from PGA. It was also proposed that early degradation of PLGA fibers may render a positive effect on chondrogenesis by leaving new spaces for cells to further fill in and produce new intercellular matrix, which in turn may facilitate the formation of more cell-matrix and cell-cell contact.

The complete removal of the anterior horn of the canine medial meniscus, without subsequent treatment, resulted in only a muted healing response primarily composed of scar tissue formation. No empty defects had complete or nearcomplete filling with repair tissue, indicating that the defect created in our model was a critical one. The implantation of the composite scaffold without cells into the meniscal defect did produce better repair compared to that in the empty defect controls. The thickness of the repair tissue was significantly thicker after 12 weeks. The histological and immunohistochemical analyses indicated that this repair tissue was mainly fibrous and scar-like. Scaffolds loaded with myoblasts and pre-cultured in chondrogenic medium prior to the insertion into meniscal defects resulted in significantly better meniscal defect filling and meniscal regeneration compared to the repair after implantation of cell-free composites. The repair tissue after myoblast-based repair revealed a more meniscus-like 
appearance than that of the repair tissue of the controls with cell-free composite scaffolds. Good integration of the repair tissue with the host meniscus at the defect edges could be seen macroscopically and ultrastructurally after meniscal repair with myoblasts loaded implants. Results of histological and immunohistochemical evaluation of the normal canine meniscus indicated that the anterior horn of the medial meniscus contained type II collagen. Thus, the presence of type II collagen in the repair tissue was an important parameter to examine. Nine of the 12 menisci with pre-cultured implants had evidence of type II collagen in the repair tissue, indicating retention of the type II collagen-rich implant.

The cell-loaded and pre-cultured implants did not completely restore the surface area and the tissue quality of the normal meniscus. Therefore, modifications are necessary to improve the meniscus implant. Also, long-term studies with functional assessments of the repair tissue are important. One limitation of the canine as a model for meniscus repair is that it does not have a gait pattern close to that of humans. Therefore, the implantation of the stem cell-loaded scaffolds in larger animal models is necessary before clinical use. Despite these limitations, this study demonstrates that regeneration of an important musculoskeletal structure, such as the meniscus, can be achieved using a scaffold and stem cell-based tissue engineering approach.

\section{Acknowledgements}

This study was supported by the Shanghai Natural Science Foundation, China (no. 09ZR1425500).

\section{References}

1. Voloshin AS and Wosk J: Shock absorption of meniscectomized and painful knees: a comparative in vivo study. J Biomed Eng 5: 157-161, 1983.

2. Ahmed AM, Burke DL and Yu A: In-vitro measurement of static pressure distribution in synovial joints-part II: retropatellar surface. J Biomech Eng 105: 226-236, 1983.

3. Hart R, Janecek M, Siska V, Kucera B and Stipcák V: Correlation of long-term clinical and radiological results after meniscectomies. Acta Chir Orthop Traumatol Cech 72: 304-307, 2005.

4. Van der Wal RJ, Thomassen BJ and van Arkel ER: Long-term clinical outcome of open meniscal allograft transplantation. Am J Sports Med 37: 2134-2139, 2009.

5. Yamasaki T, Deie M, Shinomiya R, Yasunaga Y, Yanada S and Ochi M: Transplantation of meniscus regenerated by tissue engineering with a scaffold derived from a rat meniscus and mesenchymal stromal cells derived from rat bone marrow. Artif Organs 32: 519-524, 2008.

6. Webber RJ, York JL, Vanderschilden JL and Hough AJ Jr: An organ culture model for assaying wound repair of the fibrocartilaginous knee joint meniscus. Am J Sports Med 17: 393-400, 1989.

7. Baker BM, Nathan AS, Huffman GR and Mauck RL: Tissue engineering with meniscus cells derived from surgical debris. Osteoarthritis Cartilage 17: 336-345, 2009.
8. Kang SW, Son SM, Lee JS, Lee ES, Lee KY, Park SG, Park JH and Kim BS: Regeneration of whole meniscus using meniscal cells and polymer scaffolds in a rabbit total meniscectomy model. J Biomed Mater Res A 78: 659-671, 2006.

9. Ishida K, Kuroda R, Miwa M, Tabata Y, Hokugo A, Kawamoto T, Sasaki K, Doita M and Kurosaka M: The regenerative effects of platelet-rich plasma on meniscal cells in vitro and its in vivo application with biodegradable gelatin hydrogel. Tissue Eng 13: 1103-1112, 2007.

10. Peretti GM, Gill TJ, Xu JW, Randolph MA, Morse KR and Zaleske DJ: Cell-based therapy for meniscal repair: a large animal study. Am J Sports Med 32: 146-158, 2004.

11. Lu SH, Yang AH, Wei CF, Chiang HS and Chancellor MB: Multi-potent differentiation of human purified muscle-derived cells: potential for tissue regeneration. BJU Int 105: 1174-1180, 2009.

12. Zhou G, Liu W, Cui L, Wang X, Liu T and Cao Y: Repair of porcine articular osteochondral defects in non-weight-bearing areas with autologous bone marrow stromal cells. Tissue Eng 12: 3209-3221, 2006

13. Zhu W, Wang Y, Qiu G and Chen B: Characterization of the purification and primary culture of adult canine myoblasts in vitro. Mol Med Rep 3: 463-468, 2010.

14. Asakura A, Komaki M and Rudnicki M: Muscle satellite cells are multipotential stem cells that exhibit myogenic, osteogenic and adipogenic differentiation. Differentiation 68: 245-253, 2001.

15. Matsushita T, Matsui N, Fujioka H, Kubo S, Kuroda R, Kurosaka M and Yoshiya S: Expression of transcription factor sox9 in rat L6 myoblastic cells. Connect Tissue Res 45: 164-173, 2004.

16. Goldring K, Partridge T and Watt D: Muscle stem cells. J Pathol 197: 457-467, 2002.

17. Day CS, Kasemkijwattana C, Menetrey J, Floyd SS Jr, Booth D, Moreland MS, Fu FH and Huard J: Myoblast-mediated gene transfer to the joint. J Orthop Res 15: 894-903, 1997.

18. Koning M, Harmsen MC, van Luyn MJ and Werker PM: Current opportunities and challenges in skeletal muscle tissue engineering. J Tissue Eng Regen Med 3: 407-415, 2009.

19. Singh D, Nayak V and Kumar A: Proliferation of myoblast skeletal cells on three-dimensional supermacroporous cryogels. Int J Biol Sci 6: 371-381, 2010.

20. Marsano A, Millward-Sadler SJ, Salter DM, Adesida A, Hardingham T, Tognana E, Kon E, Chiari-Grisar C, Nehrer S, Jakob M and Martin I: Differential cartilaginous tissue formation by human synovial membrane, fat pad, meniscus cells and articular chondrocytes. Osteoarthritis Cartilage 15: 48-58, 2007.

21. Lu SH, Yang AH, Wei CF, Chiang HS and Chancellor MB: Multi-potent differentiation of human purified muscle-derived cells: potential for tissue regeneration. BJU Int 105: 1174-1180, 2009.

22. Stern-Straeter J, Bran G, Riedel F, Sauter A, Hörmann K and Goessler UR: Characterization of human myoblast cultures for tissue engineering. Int J Mol Med 21: 49-56, 2008.

23. Moran JM, Pazzano D and Bonassar LJ: Characterization of polylactic acid-poly-glycolic acid composites for cartilage tissue engineering. Tissue Eng 9: 63-70, 2003.

24. Cui L, Wu Y, Cen L, Zhou H, Yin S, Liu G, Liu W and Cao Y: Repair of articular cartilage defect in non-weight-bearing areas using adipose-derived stem cell-loaded polyglycolic acid mesh. Biomaterials 30: 2683-2693, 2009.

25. Zwingmann J, Mehlhorn AT, Sudkamp N, Stark B, Dauner M and Schmal H: Chondrogenic differentiation of human articular chondrocytes differs in biodegradable PGA/PLA scaffolds. Tissue Eng 13: 2335-2343, 2007. 